\title{
Differing effects on gall-bladder motility of lanreotide SR and octreotide LAR for treatment of acromegaly
}

\author{
H E Turner ${ }^{1}$, D R M Lindsell ${ }^{2}$, A Vadivale ${ }^{1}$, A V Thillainayagam ${ }^{3}$ and J A H Wass ${ }^{1}$ \\ Departments of ${ }^{1}$ Endocrinology, Radcliffe Infirmary, Oxford, ${ }^{2}$ Radiology, John Radcliffe Hospital, Oxford and ${ }^{3}$ Gastroenterology, Charing Cross \\ Hospital, London, UK \\ (Correspondence should be addressed to J A H Wass, Department of Endocrinology, Radcliffe Infirmary, Woodstock Road, Oxford OX2 6HE, UK)
}

\begin{abstract}
Background: Octreotide treatment may be associated with gall stone development in up to $50 \%$ of patients with acromegaly. Two new sustained-release formulations of somatostatin analogue have been recently developed: lanreotide SR (Somatuline) and octreotide LAR (Sandostatin LAR). The incidence of gall-stone development in patients receiving these drugs has been shown to be less than $20 \%$, but the duration of follow-up has been limited.

Objective: Prospectively to assess and compare the effects of the two new long-acting somatostatin agonists on gall bladder motility in patients with acromegaly.

Method and patients: Eleven patients with active acromegaly were studied. Three patients had asymptomatic gall stones at the start of the study. Ultrasound scans were performed before commencement of the treatment, and repeated during treatment with lanreotide SR and octreotide LAR. The presence of gall stones, fasting gall bladder volume (FV), residual volume (RV) and maximal percentage gall bladder emptying were measured.

Results: One patient developed asymptomatic small gall stones after treatment with octreotide LAR for 4 months. FV and RV were both significantly larger when patients received treatment with lanreotide SR or octreotide LAR compared with pretreatment values $(P<0.05$ for both). Maximal percentage gall bladder emptying was significantly reduced in patients receiving lanreotide SR or octreotide LAR compared with pretreatment $(P<0.01)$, but was less impaired in patients receiving lanreotide SR than in those receiving octreotide LAR $(P<0.01)$.

Conclusions: Gall bladder motility is impaired in patients receiving either of these new long-acting preparations, and long-term follow-up will be needed to establish the true incidence of gall stones.
\end{abstract}

European Journal of Endocrinology 141 590-594

\section{Introduction}

The somatostatin analogue, octreotide, has been used to treat acromegaly for more than 10 years (1). Two new sustained-release formulations of somatostatin analogue have recently been developed: lanreotide SR (Somatuline) and octreotide LAR (Sandostatin LAR). In contrast to thrice daily subcutaneous administration, these drugs need to be administered only every 7-14 days or every 28 days, respectively. They have both been shown to provide effective growth hormone-lowering treatment for patients with acromegaly $(2-8)$.

It has been recognised for many years that octreotide treatment may be associated with the development of gall stones in up to $50 \%$ of patients with acromegaly ( 9 , $10)$ and also in patients with other conditions such as carcinoid and islet cell tumours (11). These gall stones are usually asymptomatic and only rarely need definitive management (12). Gall-stone prevalence in the general population ranges from approximately 10 to $25 \%$.
The mechanism of development of octreotide-induced gall stones is related, at least in part, to inhibition of cholecystokinin (CCK) secretion and reduced gall bladder emptying (13-15), in addition to prolonged large-bowel transit times (15). It has been clearly demonstrated that octreotide leads both to suppression of cholecystokinin secretion $(16,17)$ and to decreased sensitivity to cholecystokinin $(18,19)$. In addition, octreotide produces lithogenic changes in bile composition, leading to increased deoxycholic acid conjugates and cholesterol saturation of gall-bladder bile $(12,15,20)$. Marked reductions in gall bladder emptying have been demonstrated in patients receiving octreotide treatment, both acutely and with prolonged treatment (13-15).

Treatment with ursodiol has been shown to reverse the abnormalities in some patients with acromegaly who are receiving octreotide (21-23). It has been suggested that timing octreotide injections in relation to meals (24), or periodic breaks in treatment may reduce the incidence of gall-stones $(12,25)$. Gall-bladder 
contractility has been shown to return to normal within 2 weeks of discontinuation of octreotide treatment (26).

There have been some studies of the effectiveness of both octreotide LAR and lanreotide SR in patients with acromegaly that showed that gall-bladder abnormalities, including gall stones, were associated with these drugs, but that their incidence was low $(<20 \%)(27)$, and it has been suggested that the incidence of gall stones in patients receiving these newer, long-acting somatostatin analogues may be lower. A study comparing treatment with continuous subcutaneous infusion of octreotide and treatment by intermittent subcutaneous doses demonstrated that octreotide injections led to impaired gall-bladder contraction for at least $4 \mathrm{~h}$, but that cholecystokinin release was normal $8 \mathrm{~h}$ after an injection, whereas, although gall bladder contraction was less impaired during continuous subcutaneous octreotide treatment, CCK concentrations remained very low (24). Thus it might be expected that continual exposure to lower somatostatin concentrations may be associated with less impairment of gall-bladder motility. There have been no previously reported studies assessing the effect of these long-acting preparations on gallbladder motility or comparing the effects of the two drugs on the gall bladder in the same patients.

The aim of this study was prospectively to assess and compare the effects of the two new long-acting somatostatin agonists on gall-bladder motility in patients with acromegaly.

\section{Patients and methods}

\section{Patients}

We studied 11 patients (Table 1) (mean age 59.6 years, range 45-71 years, five women) with active acromegaly (mean duration 6.6 years) as defined by clinical features and failure of circulating growth hormone $(\mathrm{GH})$ concentrations to suppress below $2 \mathrm{mU} / \mathrm{l}$ after a $75 \mathrm{~g}$ oral glucose load. Three patients had gall stones at the start of the study, all of whom had been receiving prior octreotide treatment for a mean of 4 years (range 1-7 years). No patient had required any therapeutic intervention for cholelithiasis. Patients receiving subcutaneous octreotide $(n=4)$ underwent a washout period of at least 2 weeks before commencing the study protocol. The other patients had not previously been treated with somatostatin agonists. The study procedure was approved by the local research and ethics committee, and all patients gave their written informed consent to participate.

\section{Study protocol}

Ultrasound scans of the gall bladder were performed in all but one patient before the commencement of longacting somatostatin analogue treatment. In six patients, the scans were repeated (midway between injections) after at least 4 months treatment with lanreotide SR. Four patients were receiving injections every 10 days; three received them every 7 days. These patients then had their treatment changed (after a washout period of at least 6 weeks) to octreotide LAR, and ultrasound scans performed after at least 4 months treatment with octreotide LAR. Four patients received octreotide LAR only and had scans performed at baseline and after at least 4 months treatment with octreotide LAR. Seven patients received $20 \mathrm{mg}$ octreotide LAR and four patients received $30 \mathrm{mg}$.

The ultrasound scans were performed at $0800 \mathrm{~h}$ by a single observer (D R M L) without knowledge of the treatment, using a V328, 3.5 MHz sector transducer on an Acuson XP10 machine. The presence of gall stones was noted. The fasting volume (FV) of the gall bladder was calculated using the measurements of the length (l), height $(\mathrm{h})$ and width $(\mathrm{w})$ of the gall bladder $(\mathrm{V}=\pi$ / $6 \times \operatorname{lwh})(13)$. These measurements were repeated 20 and $40 \mathrm{~min}$ after the patient had ingested $250 \mathrm{ml}$ Ensure (Abbott Laboratories, Maidenhead, Berks, UK) and the smallest gall bladder volume determined (residual

Table 1 Patient characteristics.

\begin{tabular}{|c|c|c|c|c|c|c|}
\hline \multirow[b]{2}{*}{ Patient } & \multirow{2}{*}{$\begin{array}{c}\text { Age } \\
\text { (yr) }\end{array}$} & \multirow[b]{2}{*}{ Sex } & \multirow{2}{*}{$\begin{array}{c}\text { Year of } \\
\text { diagnosis }\end{array}$} & \multirow{2}{*}{$\begin{array}{l}\text { Previous } \\
\text { octreotide† } \\
\text { (years) }\end{array}$} & \multicolumn{2}{|c|}{ Gallstones at baseline } \\
\hline & & & & & Presence & Size $(\mathrm{cm})$ \\
\hline 1 & 60 & $\mathrm{~F}$ & 1988 & 7 & + & 0.6 \\
\hline 2 & 71 & M & 1995 & & - & \\
\hline 3 & 69 & M & 1978 & & - & \\
\hline 4 & 44 & M & 1989 & 1 & + & 1 \\
\hline 5 & 55 & M & 1990 & 4 & + & 1 \\
\hline 6 & 51 & $\mathrm{~F}$ & 1986 & & - & \\
\hline 7 & 70 & M & 1992 & 0.5 & - & \\
\hline 8 & 52 & $\mathrm{~F}$ & 1996 & & - & \\
\hline 9 & 60 & $\mathrm{~F}$ & 1996 & & - & \\
\hline 10 & 71 & $\mathrm{~F}$ & 1991 & & - & \\
\hline 11 & 53 & M & 1986 & & - & \\
\hline
\end{tabular}

† Duration of previous treatment.

+ , gallstones present; -, no gallstones. 
Table 2 Ultrasound scan results.

\begin{tabular}{|c|c|c|c|c|c|c|c|c|c|c|c|c|}
\hline \multirow[b]{2}{*}{ Patient } & \multicolumn{4}{|c|}{ Baseline } & \multicolumn{4}{|c|}{ Lanreotide SR } & \multicolumn{4}{|c|}{ Octreotide LAR } \\
\hline & $\begin{array}{l}\mathrm{FV} \\
(\mathrm{ml})\end{array}$ & $\begin{array}{l}\text { RV20 } \\
\text { (ml) }\end{array}$ & $\begin{array}{c}\text { RV40 } \\
\text { (ml) }\end{array}$ & $\begin{array}{c}E \\
(\%)\end{array}$ & $\begin{array}{l}\text { FV } \\
\text { (ml) }\end{array}$ & $\begin{array}{c}\text { RV20 } \\
\text { (ml) }\end{array}$ & $\begin{array}{l}\text { RV40 } \\
\text { (ml) }\end{array}$ & $\begin{array}{c}E \\
(\%)\end{array}$ & $\begin{array}{l}\mathrm{FV} \\
(\mathrm{ml})\end{array}$ & $\begin{array}{c}\text { RV20 } \\
\text { (ml) }\end{array}$ & $\begin{array}{c}\text { RV40 } \\
\text { (ml) }\end{array}$ & $\begin{array}{c}E \\
(\%)\end{array}$ \\
\hline 1 & 54 & 12 & 7 & 87 & 89 & 52 & 24 & 73 & 97 & 45 & 36 & 62 \\
\hline 2 & 60 & 4 & 4 & 94 & 97 & 70 & 70 & 28 & 37 & 37 & 37 & 0 \\
\hline 3 & 16 & 3 & 1 & 94 & 15 & 3.5 & 3.5 & 76 & 12 & 10 & 8 & 33 \\
\hline 4 & 10.5 & 3 & 2 & 81 & 15 & 8.5 & 8.5 & 45 & 41 & 41 & 41 & 0 \\
\hline 5 & 66 & 10 & 8 & 88 & 73 & 44 & 39 & 47 & 78 & 65 & 56 & 28 \\
\hline 6 & & & & & 34 & 16 & 14 & 58 & 44 & 38 & 38 & 14 \\
\hline 7 & 50 & 4 & 4 & 92 & 87 & 36 & 27 & 69 & 60 & 44 & 33 & 45 \\
\hline 8 & 26 & 4.6 & 4.6 & 82 & & & & & 62 & 48 & 43 & 31 \\
\hline 9 & 32 & 8 & 5 & 84 & & & & & 72 & 21 & 31 & 71 \\
\hline 10 & 36 & 9 & 15 & 75 & & & & & 44 & 31 & 23 & 48 \\
\hline 11 & 40 & 15 & 15 & 63 & & & & & 89 & 50 & 50 & 44 \\
\hline
\end{tabular}

FV, fasting gall-bladder volume; RV20, gall-bladder volume $20 \mathrm{~min}$ after Ensure; RV40, gall-bladder volume 40 min after Ensure; E, maximal gall-bladder emptying, calculated as $1-\mathrm{RV} / \mathrm{FV} \times 100$.

volume, RV). The maximal percentage gall bladder emptying was calculated from the formula 1-RV/ $\mathrm{FV} \times 100(13)$

\section{Statistical analysis}

Wilcoxon's rank sum test was used to compare the two groups. A value of $P<0.05$ was chosen to represent statistical significance.

\section{Results}

Three patients had gall stones before starting longacting somatostatin analogue treatment. All three had received prior treatment with subcutaneous octreotide for a mean of 4 years (range 1-7 years). The ultrasound appearance of the stones did not change significantly during the course of the study period. A further patient developed asymptomatic small gall stones after treatment with octreotide LAR for 4 months.

Fasting gall-bladder volumes were significantly greater when patients were receiving treatment with either lanreotide SR or octreotide LAR, compared with the pretreatment ultrasound scans $(P<0.05$ for both; Table 2). There was no difference between fasting gallbladder volumes in patients receiving either drug. The gall bladder residual volumes were significantly greater compared with pretreatment values when patients were treated with either drug $(P<0.01$ for both drugs; Fig. 1). There was no difference between the residual volumes in patients receiving either of the two drugs.

Maximal percentage gall bladder emptying was significantly reduced when patients received lanreotide SR or octreotide LAR compared with the pretreatment scans $(P<0.01$ for both; Fig. 1$)$. There was no difference in fasting or residual gall-bladder volumes or maximal gall-bladder emptying when patients with gall stones were compared with those without. Maximal gall bladder emptying was significantly less when patients were receiving octreotide LAR than in those treated with lanreotide SR $(P<0.01)$.

\section{Discussion}

This study clearly demonstrates that gall-bladder emptying is impaired in patients with acromegaly receiving treatment with either of the new long-acting somatostatin analogues. This is similar to the effects of the shorter-acting somatostatin analogue, octreotide. In addition, the fasting gall-bladder volumes were significantly greater when patients were receiving long-acting somatostatin agonist treatment. The greatly impaired gall-bladder contraction was further reflected in significantly larger gall-bladder residual volumes after the standard stimulation by ingestion of Ensure. As the duration of follow-up of patients treated with these newer long-acting analogues increases, the incidence of gall-stone development may be expected to rise, although the proportion of patients with gall stones who are symptomatic is likely to remain small.

The significantly more marked impairment of gallbladder contractility in patients receiving treatment with octreotide LAR compared with those taking lanreotide SR may be related to overall drug effectiveness. Trough concentrations of $1.13 \mathrm{ng} / \mathrm{ml}$ for lanreotide SR and $1.3 \mathrm{ng} / \mathrm{ml}$ for octreotide LAR are very similar $(2,3)$ and, clearly, differences in effects of each drug will also depend on potency at receptor subtypes. Recent data from our unit suggest that. although there is no overall difference in proportion of patients who achieve a mean $\mathrm{GH}$ below a target of $5 \mathrm{mU} / \mathrm{l}$, the overall mean GH is significantly lower when patients receive treatment with octreotide LAR compared with those given lanreotide SR (28). Therefore the difference in gall-bladder emptying may simply reflect differences in efficacy of the drug. However, the difference in gallbladder emptying could be exploited, as a patient who responds to both drugs, but who has gall stones or 


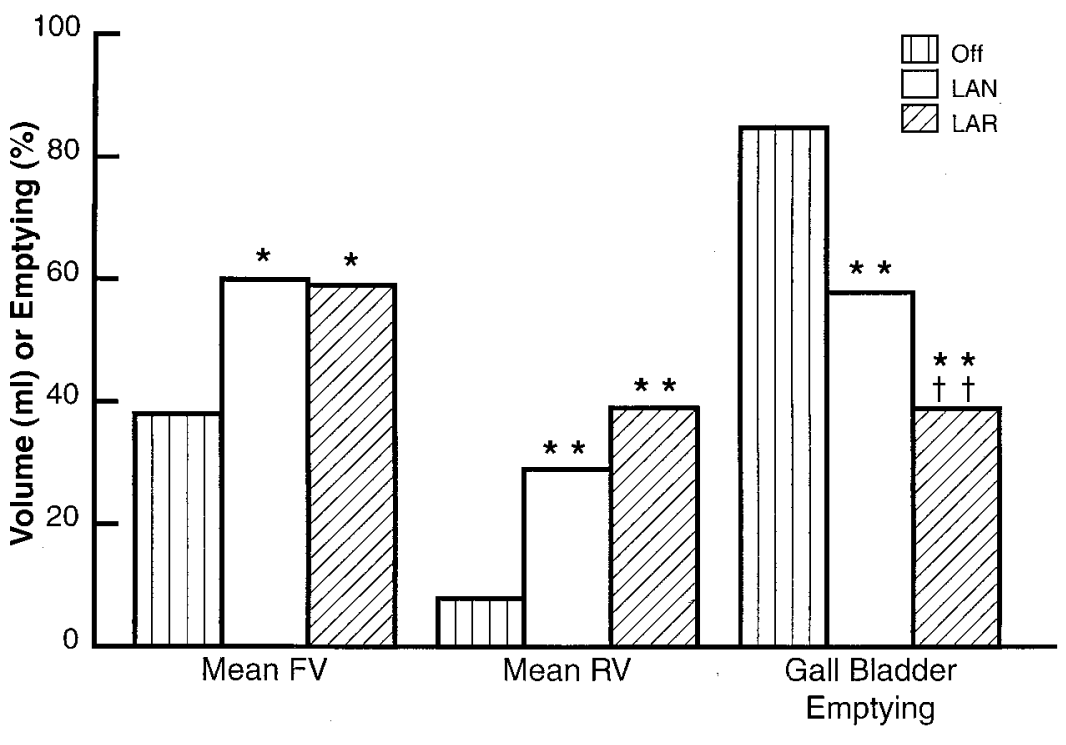

Figure 1 Gall-bladder emptying (calculated as $1-\mathrm{RV} / \mathrm{FV} \times 100 \%)$, mean fasting volume (FV) $(\mathrm{ml})$ and mean residual volume $(\mathrm{RV})(\mathrm{ml})$ in patients with acromegaly, before treatment with lanreotide SR or octreotide LAR (Off) or while receiving lanreotide $S R$ (LAN) or octreotide LAR (LAR). Significant differences: ${ }^{\star} P<0.05,{ }^{*} P<0.01$, compared with off drugs; $\dagger \dagger P<0.01$ compared with lanreotide SR. biliary abnormalities, may be less likely to develop further stones if receiving lanreotide SR.

Further long-term data are required on the incidence of gall stones in patients receiving treatment with either of these drugs. The increased convenience of depot preparations and the awareness of the importance of control of GH concentrations in acromegaly are likely to lead to increasing numbers of patients with acromegaly receiving treatment with these drugs. The potential complication of gall-stone development should not be forgotten, and patients should be monitored for this potential complication of treatment, although the likelihood of symptomatic cholelithiasis should remain low.

\section{Acknowledgements}

We thank Ipsen Limited and Novartis Pharmaceuticals for providing the drugs.

\section{References}

1 Vance ML \& Harris AG. Long-term treatment of 189 acromegalic patients with the somatostatin analog octreotide. Archives of Internal Medicine 1991151 1573-1578.

2 Morange I, De Boisvilliers F, Chanson P, Lucas B, Dewailly D, Catus FT et al. Slow release lanreotide treatment in acromegalic patients previously normalised by octreotide. Journal of Clinical Endocrinology and Metabolism 199479 145-151.

3 Stewart PM, Kane KF, Stewart SE, Lancranjan I \& Sheppard MC. Depot long-acting somatostatin analog (Sandostatin-LAR) is an effective treatment for acromegaly. Journal of Clinical Endocrinology and Metabolism 199580 3267-3272.

4 Al-Maskari M, Gebbie J \& Kendall-Taylor P. The effect of a new slow-release, long-acting somatostatin analogue, lanreotide, in acromegaly. Clinical Endocrinology 199645 415-421.

5 Giusti M, Gussoni G, Cuttica CM, Giordano G \& the Italian Multicenter Slow-Release Lanreotide Study Group. Effectiveness and tolerability of slow release lanreotide treatment in active acromegaly: six month report on an Italian multicenter study.
Journal of Clinical Endocrinology and Metabolism 199681 20892097.

6 Caron P, Morange-Romas I, Cogne M \& Jaquet P. Three year follow-up of acromegalic patients treated with intramuscular slow-release lanreotide. Journal of Clinical Endocrinology and Metabolism 199782 18-22.

7 Fløgstad AK, Halse J, Bakke S, Lancranjan I, Marbach P, Bruns C et al. Sandostatin LAR in acromegalic patients: long term treatment. Journal of Clinical Endocrinology and Metabolism 1997 82 23-28.

8 Davies PH, Stewart SE, Lancranjan I, Sheppard MC \& Stewart PM Long-term therapy with long-acting octreotide (Sandostatin LAR) for the management of acromegaly. Clinical Endocrinology 1998 48 311-316.

9 Dowling RH, Hussaini SH, Murphy GM, Besser GM \& Wass JAH Gallstones during octreotide therapy. Metabolism 199241 2233.

10 Eastman RC, Arakaki RF, Shawker T, Schock R, Roach P, Comi RJ et al. A prospective examination of octreotide gall-bladder changes in acromegaly. Clinical Endocrinology 199236 265-269.

11 Trendle MC, Moertel CG \& Kvols LK. Incidence and morbidity of cholelithiasis in patients receiving chronic octreotide for metastatic carcinoid and malignant islet cell tumours. Cancer 199779 830-834.

12 Redfern JS \& Fortuner WJ. Octreotide biliary tract dysfunction and gallstone formation: pathophysiology and management. American Journal of Gastroenterology $1995901042-1052$.

13 Catnach SM, Anderson JV, Fairclough PD, Trembath RC, Wilson PAJ, Parker E et al. Effect of octreotide on gall stone prevalence and gall bladder motility in acromegaly. Gut 199334 270-273.

14 Stolk MF, van Erpecum KJ, Koppeschaar HP, Samsom M, Smout AJ, Akkermans LM et al. Effect of octreotide on fasting gall bladder emptying, antroduodenal motility and motilin release in acromegaly. Gut 199536 755-760.

15 Hussaini SH, Pereira SP, Veysey MJ, Kennedy C, Jenkins P, Murphy GM et al. Roles of gall bladder emptying and intestinal transit in the pathogenesis of octreotide induced gall bladder stones. Gut 199638 775-783.

16 Mitsukawa T, Takemura J, Nishizono F, Nakatsuru K, Ohgo S \& Matsukura S. Effects of atropine, proglumide, and somatostatin analogue ((SMS 201-995) on bombesin-induced octreotide contraction and CCK secretion in humans. American Journal of Gastroenterology 198984 1371-1374.

17 Hopman WP, Van Liessum PA, Pieters GF, Jansen JB, Lamers CB, Smals AG et al. Postprandial gallbladder motility and plasma 
cholecystokinin at regular time intervals after injection of octreotide in acromegalics on long-term treatment. Digestive Diseases 199237 1685-1690.

18 van Liessum PA, Hopman WP, Pieters GF, Jansen JB, Smals AG, Rosenbusch G et al. Postprandial gall bladder motility during long term treatment with the long-acting somatostatin analog SMS201-995 in acromegaly. Journal of Clinical Endocrinology and Metabolism 198969 557-562.

19 Ewins DL, Javaid A, Coskeran PB, Shah S, Butler J, Deprez PH, Miell J et al. Assessment of gallbladder dynamics, cholecystokinin release and the development of gallstones during octreotide therapy for acromegaly. Quarterly Journal of Medicine 199283 295-306.

20 Erlinger S, Chanson P, Dumont M, Ponsot P, Warnet A \& Harris AG. Effects of octreotide on biliary lipid composition and occurrence of cholesterol crystals in patients with acromegaly. A prospective study. Digestive Diseases 199439 2384-2388.

21 Montini M, Gianoloa D, Pagani MD, Perdroncelli A, Caldara R, Gherardi $\mathrm{F}$ et al. Cholelithiasis and acromegaly: therapeutic strategies. Clinical Endocrinology $199440401-406$.

22 Tauber JP, Poncet MF, Harris AG, Barthel HR, SimonettaChateauneuf $\mathrm{C}$, Buscail L et al. The impact of continuous infusion of octreotide on gallstone formation in acromegalic patients. Journal of Clinical Endocrinology and Metabolism $1995803262-3266$.

23 Avila NA, Shawker TH, Roach P, Bradford MH, Skarulis MC \& Eastman R. Sonography of gall bladder abnormalities in acromegaly patients following octreotide and ursodiol therapy: incidence and time course. Journal of Clinical Ultrasound 199826 289-294.

24 Stolk MF, van Erpecum KJ, Koppeschaar HP, de Bruin WI, Jansen JB, Lamers CB et al. Postprandial gall bladder motility and hormone release during intermittent and continuous subcutaneous octreotide treatment in acromegaly. Gut 199334 808813.

25 Rhodes M, James RA, Bird M, Clayton B, Kendall-Taylor P \& Lennard TW. Gall bladder function in acromegalic patients taking long-term octreotide: evidence of rebound hypermobility on cessation of treatment. Scandinavian Journal of Gastroenterology $199227115-118$.

26 Shi YF, Zhu XF, Harris AG, Zhang JX \& Deng JY. Restoration of gall bladder contractility after withdrawal of long-term octreotide therapy in acromegalic patients. Acta Endocrinologica 1993129 207-212.

27 Gillis JC, Noble S \& Goa KL. Octreotide long-acting release (LAR). Drugs 199753 681-699.

28 Turner HE, Vadivale A, Keenan J \& Wass JAH. A comparison of lanreotide and octreotide LAR for treatment of acromegaly. Clinical Endocrinology $199951275-280$.

Received 9 March 1999

Accepted 12 August 1999 